\title{
O PAPEL DO PEDAGOGO NO AMBIENTE HOSPITALAR
}

\author{
THE ROLE OF THE PEDAGOGIST IN THE HOSPITAL ENVIRONMENT
}

\author{
Tatiane Ferreira Gomes ${ }^{1}$ \\ Mary Helen Aragão Sousa ${ }^{2}$
}

RESUMO: Este trabalho trata da participação ativa do pedagogo no processo contínuo de ensino aprendizagem de estudantes em situação de hospitalização, abrangendo desde a apresentação da Pedagogia Hospitalar, definindo o papel do pedagogo e suas funções dentro do contexto que se apresenta, mostrando de forma ampla como se dá o trabalho prático desse profissional e sua importância para garantir os direitos do estudante sob seus cuidados. Expõe ainda a necessidade de um trabalho multidisciplinar efetivo, que transforme a teoria em prática de forma satisfatória. $\mathrm{O}$ objetivo geral dessa pesquisa é demonstrar a relevância da ação do profissional de pedagogia no ambiente hospitalar, se desdobrando nos objetivos específicos de analisar as formas de inclusão, na busca de compreender os desafios enfrentados pelos pedagogos para por em prática uma educação de qualidade dentro das limitações impostas pela situação do estudante em situação de internamento hospitalar. A metodologia utilizada é a revisão integrativa da literatura, a partir da busca de artigos relacionados à temática na plataforma online Scielo, que, quando analisados, proporcionaram a percepção sobre a importância da pedagogia hospitalar na contribuição do ensino de estudantes hospitalizados.

Palavras-chave: Equipe Multidisciplinar. Formação Especializada. Pedagogia Hospitalar. Educação Contínua.

ABSTRACT: This work deals with the active participation of the pedagogue in the continuous teaching process of learning students in hospitalization situations, covering since the presentation of Pedagogy Hospital, its specificities as an educational modality, defining the role of the pedagogue and its functions within the context that is presented, showing broadly how this professional's practical work takes place and its importance in guaranteeing the rights of the student in their care. They also expose the need for an effective multidisciplinary work that transforms theory into practice in a satisfactory way. The general objective of this research is to demonstrate the relevance of the action of the pedagogical professional in the hospital environment, unfolding in the specific objectives of analyzing the ways of inclusion of educators in this differentiated pedagogical practice, providing interned students with a pedagogicalemotional treatment consistent with their condition. Enable professionals in both areas to work with the same purpose. The methodology used is the integrative literature review, based on the search for articles related to the theme on the Scielo online platform, which, when analyzed, provided the perception about the challenges of the hospital educator's performance, in addition to realizing the importance of his role in the continuity of education of hospitalized.

Keywords: Multidisciplinary team. Specialized Training. Hospital Pedagogy. Continuing Education

${ }^{\mathrm{I} G r a d u a n d a}$ de licenciatura em Pedagogia pela faculdade Ieducare - FIED, Tianguá-CE. http://lattes.cnpq.br/o336540889464996

${ }^{2}$ Mestre em Ciências da Educação pela Universidade San Lorenzo - UNISAL, Paraguai. http://lattes.cnpq.br/9224229685697713 


\section{INTRODUÇÃO}

A educação e a saúde são dois dos direitos fundamentais previstos na Constituição Federal em seu artigo $5^{\circ}$ que assiste a população brasileira. As crianças e os adolescentes têm esse direito reafirmando no (ECA) Estatuto Da Criança e Adolescentes (1990). Por se tratar de direitos fundamentais, as crianças e adolescentes em situação hospitalar têm resguardado o seu direito a continuar com seu processo de escolarização mesmo em um ambiente diverso ao da escola. Muito embora seja uma área ainda não tão conhecida, a Pedagogia Hospitalar é prevista pela Lei $\mathrm{n}^{\circ} 9.394$ no artigo $4^{\circ}$. A da Lei de Diretrizes e Bases da Educação Nacional (LDB) Lei n9394/96 e regulamentada pelas Diretrizes Nacionais para a Educação Especial Básica.

No entanto, ao se aprofundar no tema, percebe-se que a pedagogia hospitalar é pouco exercida. Grande parte das instituições escolares não contam com profissionais com a formação adequada para essa prática laboral. Foi precisamente por tomar conhecimento dessa modalidade de ensino diferenciada que surgiu a motivação para essa pesquisa, já que nos casos de alunos que estejam impossibilitados de estudar regularmente por conta de internamento hospitalar, as escolas preferem recorrer a outros processos, como repetição de nota o que compromete o processo de aprendizagem dos alunos.

Esse impedimento, (quer seja transitório ou por tempo indeterminado), do estudante frequentar o ambiente escolar mostra a necessidade desta área da pedagogia ser estudada e colocada como pauta de discussão junto aos órgãos de educação e saúde, para a implementação políticas públicas que permitam a efetivação das ações requeridas por essa área da pedagogia. Por essas assertivas, este trabalho justifica-se pela necessidade de se colocar em prática um direito inerente e garantido legalmente aos alunos na situação acima exposta. A realidade tem que se adaptar a teoria e proporcionar a esses alunos a mesma oportunidade de aprendizagem dos demais.

Assim sendo, o objetivo geral dessa pesquisa é demonstrar a relevância da ação do profissional de pedagogia no ambiente hospitalar, se desdobrando nos objetivos específicos: Discutir a importância da pedagogia hospitalar, compreender os desafios enfrentados pelos pedagogos para dar continuidade ao processo educativo do estudante em situação de 
internamento hospitalar; identificar a continuidade dos estudos como um direito que assiste a crianças e adolescentes em situação hospitalar.

O marco teórico que embasa esse trabalho de pesquisa se fundamenta em autores renomados que se debruçaram sobre a temática como Libâneo et al (2013), Ortega et al (2018) e Ortiz \& Freitas (2013), entre outros, dando a devida idoneidade e base epistemológica necessária ao bom desenvolvimento da pesquisa.

O percurso metodológico se caracteriza como revisão integrativa, nas fontes acima citadas e artigos da base de dados Scielo devidamente referenciados e cuja estrutura da metodologia atende aos seus princípios básicos, cuja pergunta norteadora é: Qual a relevância de pedagogo na modalidade de Pedagogia Hospitalar? Os outros itens, como amostragem na literatura, análise crítica dos estudos incluídos, discussão dos resultados, serão contemplados nos títulos e subtítulos da pesquisa. Ao final, deve-se observar se a pesquisa teve seus objetivos plenamente atingidos.

Os critérios de inclusão e exclusão de artigos foram publicações compreendidas entre o período de 2016 a 2020, no idioma da língua portuguesa, inseridos na temática analisada. Para chegar até esses artigos foram empreendidas buscas na plataforma Scielo com as palavras-chave: pedagogia hospitalar e pedagogo. Os artigos foram selecionados a partir da leitura do título e da abordagem do resumo.

A principal constatação obtida dos artigos selecionados foi da quão desafiadora é a atuação do pedagogo hospitalar, além da importância do seu papel na continuidade da educação da criança hospitalizada e no atendimento aos seus familiares. O presente trabalho contém as seguintes seções: Pedagogia Hospitalar- conceito e perspectivas de aplicabilidade; a relevância do pedagogo no processo de aprendizagem no ambiente hospitalar, complementando com a relação entre a Pedagogia Hospitalar e a Pedagogia Social como instrumentos de aprendizagem.

\section{REFERENCIAL TEÓRICO}

\section{I.I. Pedagogia hospitalar: conceito e perspectivas de aplicabilidade.}

A educação é um direito fundamental previsto pela Constituição Federal de 1988, a chamada Constituição cidadã, pois prevê a educação como um direito de todos: 
A educação, direito de todos e dever do Estado e da família, será promovida e incentivada com a colaboração da sociedade, visando ao pleno desenvolvimento da pessoa, seu preparo para o exercício da cidadania e sua qualificação para o trabalho. (BRASIL, 1988).

Partindo da premissa de que a educação é direito de todos, cabe ao sistema educacional $\mathrm{e}$ as escolas assegurarem direito inalienável ao estudante. Isso deve ser garantido por todos os entes federativos responsáveis pelo processo educativo, que devem garantir esse direito inclusive para crianças e adolescentes em situações de impossibilidade de frequentar o ambiente escolar por motivo de internação hospitalar. Capacitando os profissionais de educação e fornecendo condições materiais para que estes desenvolvam suas atividades em ambiente escolar:

É assegurado atendimento educacional, durante o período de internação, ao aluno da educação básica internado para tratamento de saúde em regime hospitalar ou domiciliar por tempo prolongado, conforme dispuser o Poder Público em regulamento, na esfera de sua competência federativa (BRASIL, 1996).

Quando algum estudante se encontra nas condições acima descritas, se torna o sujeito do campo de atuação da Pedagogia Hospitalar, uma das modalidades da Educação Especial, com foco voltado especificamente para esse fim. Se há a garantia legal, também deve haver a aplicabilidade dessa prerrogativa de fundamental relevância para que os estudantes não só sejam assistidos de maneira digna e igualitária, tendo acesso ao ensino de acordo com sua seriação, para que seja garantida também a equidade de oportunidades.

A impossibilidade de frequentar a escola regular não pode significar que o aluno vá sofrer algum tipo de prejuízo na educação formal, assim como a flexibilidade que for necessária para que a qualidade do ensino seja mantida é um ponto básico da Pedagogia Hospitalar. Para consolidar esse direito e deixar ainda mais explícita a proteção aos direitos dos estudantes em situação que a saúde não os permite a frequência do sistema regular, observa-se a Lei no. 8.069, de 13 de julho de 1990, dispõe sobre o Estatuto da Criança e do Adolescente, no Título I - Das Disposições Preliminares, artigo 3:

A criança e o adolescente gozam de todos os direitos fundamentais inerentes à pessoa humana, sem prejuízo da proteção integral de que trata esta Lei, assegurando-se lhes, por lei ou por outros meios, todas as oportunidades e facilidades, a fim de lhes facultar o desenvolvimento físico, mental, moral, espiritual e social, em condições de liberdade e de dignidade. (BRASIL, I990, p.7).

Isso significa dizer que o sistema de ensino deve ter à sua disposição todos os 
recursos humanos e instrumentais que permitam ao estudante hospitalizado um ensino adaptado para suas condições, exigindo um estudo prévio das limitações causadas pelo motivo do internamento, pois a oportunização deve ser efetiva e não um paliativo temporário, sem resultados práticos na vida do aluno.

É importante frisar que a garantia legal deve vir acompanhada do conhecimento da comunidade escolar sobre tal, para que sejam assegurados ao estudante em situação hospitalar a continuação dos estudos, de forma que não tenham o ano letivo perdido e não sofram prejuízo, uma vez que não estarão tendo acesso ao conteúdo e adquirindo conhecimentos previstos para a série e a condição de aprendizagem do educando.

Os estudantes em situação hospitalar estão assegurados de todas as formas legais, o que resta saber é se essas leis são aplicadas na realidade, se a família tem o conhecimento desse direito e se as escolas estão preparadas para oferecê- lo. Para dar mais sustentabilidade a todo o aparato legal que assegura todos os direitos aos alunos em situação hospitalar, a Lei no. 9.394, de 20 de dezembro de 1996, a denominada Lei de Diretrizes e Bases da Educação Nacional (LDBEN) com necessidades educacionais de -currículos, métodos, técnicas, recursos educativos e organização específicos para atender às suas necessidades.॥. (BRASIL, I996)

Deixando expostas todas as garantias necessárias a estes estudantes, o sistema educacional deve estruturar de forma criteriosa o atendimento, que está inserido dentro das áreas da educação e saúde, que é a Pedagogia Hospitalar, ação do sistema educacional, criada justamente para o fim de garantir uma educação o mais completa possível, dentro das circunstâncias que seu estado permitir, contanto que sejam usadas todas as estratégias e metodologias diferenciadas e adequadas ao seu estado e os resultados sejam mensurados dentro do padrão de qualidade educacional que as leis garantem.

Para que essa modalidade pedagógica fosse sistematizada, foi percorrido um longo caminho, cheio de desafios, que é necessário conhecer brevemente para entender sua importância. Segundo Esteves (2016, p. 20):

Historicamente, a primeira proposta em relação à Classe Hospitalar surgiu com Henri Sellis, que inaugurou a mesma nos arredores de Paris em 1935. No entanto, no Brasil isso ocorreu apenas quinze anos mais tarde. Foi somente em i4 de agosto de 1950, na cidade do Rio de Janeiro que houve a implantação da chamada 


\begin{abstract}
Classes Especiais Hospitalares do Hospital Estadual Jesus. A Classe Hospitalar primordialmente teve como objetivo suprir as necessidades educacionais de crianças com tuberculose, porém atualmente ela abrange muito mais do que isso, pois visa sanar as necessidades escolares de crianças e adolescentes hospitalizados, independentemente do tempo que os mesmos ficarão no hospital (ESTEVES, 2016, p. 20)
\end{abstract}

Conforme foi se estruturando a colaboração entre as áreas, a Pedagogia Hospitalar se tornou uma ramificação da Pedagogia Social, que por ser mais ampla, abrange outros casos em que o direito a educação deve ser garantido.

É de grande relevância frisar que o currículo escolar deve ser mantido de acordo com a etapa escolar que o aluno esteja cursando, ressalvando suas limitações e flexibilizando de maneira lúdica a apresentação, a explanação e a interação para que se possa criar mecanismos de avaliação diferenciados sem fugir daquilo que o estudante tem o direito de acessar em termos de conhecimento. Além de manter a qualidade de aprendizagem sem que essa interfira na qualidade do tratamento do estudante/paciente. De acordo com Matos e Mugiatti (2007, p. 37):

[...] a Pedagogia Hospitalar é um processo alternativo de educação continuada que ultrapassa o contexto formal da escola, pois levanta parâmetros para o atendimento de necessidades especiais transitórias do educando, em ambiente hospitalar e/ou domiciliar. Trata-se de nova realidade multi/inter/transdisciplinar com características educativas (MATOS E MUGIATTI, 2007, p. 37).

A Pedagogia Hospitalar, além de garantir o acesso, permanência e continuidade das atividades escolares aos estudantes no ambiente de internamento, ainda cumpre a função de manter o vínculo dos mesmos enquanto cidadãos com a realidade que os cerca, contextualizando o processo de ensino aprendizagem em todos os níveis, e possibilitando, dentro dos limites, o desenvolvimento cognitivo e uma visão crítica do educando.

A Pedagogia Hospitalar deve abranger os conteúdos curriculares de modo heterodoxo, já que todos os fatores e aspectos são diferenciados de uma classe regular, e os paradigmas não se podem manter dentro de uma rigidez que impeça o estudante de exercer seu pleno direito de aprendizado.

Assim, a multidisciplinaridade vai cuidar de contextualizar e articular os saberes sistematizados e soma-los aos conhecimentos prévios do aluno, já a interdisciplinaridade terá como foco a interação dos profissionais envolvidos no processo, cada qual 
contribuindo com seus conhecimentos nas áreas de saúde, pedagogia e assistência social. Dentre elas, a transdisciplinaridade ocupa um espaço essencial pois vai fazer a junção dos conhecimentos científicos com os aspectos emocionais e psicológicos que envolvem todas ações humanísticas, que nesses casos específicos devem ser ainda mais evidentes.

A transdisciplinaridade configura-se como a interação global das várias ciências embasadas em - valores e humanização, como afeto, envolvimento, doação, magia, entre outros atributos que permeiam esse espaço vitall (MATOS; MUGIATTI, 2007, p.30). Quando a crianças/adolescente se encontra em situação hospitalar, seus parâmetros tendem a se modificar, sua visão de mundo, seus conceitos dentro de uma situação adversa, na qual ele procura o afeto e calor humano.

No entanto, existe um aspecto muito importante que não depende especificamente da Pedagogia, mas sim da parte física do processo, que é a infraestrutura para que essas aulas se desenvolvam de forma satisfatória. Por conta disso, em 2002, o Ministério da Educação, por meio de sua Secretaria de Educação Especial exemplifica:

[...] Uma sala para desenvolvimento das atividades pedagógicas com mobiliário adequado e uma bancada com pia são exigências mínimas. Instalações sanitárias próprias, completas, suficientes e adaptadas são altamente recomendáveis e espaço ao ar livre adequado para atividades físicas e ludo-pedagógicas. (BRASIL, 2002, p. 16).

São muitos os desafios que a Pedagogia Hospitalar enfrenta, desde o desconhecimento legal da sua área de atuação, passado pela falta de profissionais preparados em todas as áreas envolvidas nessa atividade legal de ensino, falta de infraestrutura e um plano viável que retire a atividade desse ramo da pedagogia do papel e a coloque onde os estudantes precisam.

\subsection{A relevância do pedagogo no processo de aprendizagem no ambiente hospitalar}

Para que se compreenda a atuação do pedagogo no contexto dessa pesquisa é necessário compreender que a Pedagogia e suas áreas não estão limitadas unicamente ao ato docente. Para Franco, Libâneo e Pimenta o papel da Pedagogia:

É promover mudanças qualitativas no desenvolvimento e na aprendizagem das pessoas, visando ajudá-las a se constituírem como sujeitos, a melhorar sua capacidade de ação $e$ as competências para viver e agir na sociedade e na comunidade. Assim o pedagogo é o profissional que cuida da formação humana 
em todos os lugares em que essa formação acontece de forma intencional e sistemática. (FRANCO; LIBÂNEO; PIMENTA, 2007, p, 89).

A educação, como pilar da formação humana, é a área que deve estar na vanguarda das mudanças sociais através da sua práxis, e isso significa dizer que o conceito de aplicação do processo de aprendizagem somente entre as quatro paredes de uma sala não se aplica, o profissional da educação deve atuar em qualquer espaço onde haja necessidade da sua intervenção, desde que tenha a formação adequada para tal.

O que ocorre, no entanto, é um acúmulo de atribuições e transferências de responsabilidade que deixam obscuras as funções precípuas do pedagogo, onde se misturam a educação que deveria ser atribuída à família, situações externas à linha de atuação desse, que não estão dentro das suas competências, trazendo por vezes uma ausência de limitações para suas ações.

Tratando mais especificamente da Pedagogia Hospitalar, se faz necessário que as políticas públicas ajam de forma convergente para que o processo aconteça de forma satisfatória, tendo cada instância suas responsabilidades objetivamente colocadas, para que sejam cumpridas a contento.

Acerca das modalidades possíveis de atendimento aos educandos em ambiente escolar, Oteiro, Dutra, Silva e Fantacini (2017, p. 20), destacam três possibilidades:

\begin{abstract}
Dentro dessa modalidade dispõem três tipos de atendimento, são eles o leito, a brinquedoteca e a classe hospitalar. Onde o primeiro diz respeito ao suporte prestado de forma individual no quarto em que o educando esteja recepcionado. Já o segundo refere-se em um espaço no qual a criança/adolescente poderá se divertir e aprender de forma lúdica. Enquanto que o terceiro concerne em uma sala específica para o atendimento educacional desses sujeitos [...] salienta que o ambulatório do hospital pode solicitar a criação de uma classe hospitalar. (oTEIRO; DUTRA; SILVA; FANTACINE, 2017, p. 20).
\end{abstract}

Esse atendimento, quer seja realizado no leito, na brinquedoteca ou em uma classe hospitalar, deve buscar sempre trazer para o ambiente hospitalar o lúdico, os jogos, as brincadeiras trazendo para o estudante a alegria em aprender, criando um vínculo entre escola e hospital para que o estudante tenha este momento de aprendizado como um momento prazeroso.

Essa busca em tornar o ensino mais atrativo para este estudante, o Ministério da Educação, através de sua Secretaria de Educação Especial, dispõe que: 


\begin{abstract}
Nas classes hospitalares, sempre que possível, devem estar disponibilizados recursos audiovisuais, como computador em rede, televisão, videocassete, máquina fotográfica, filmadora, videokê, antena parabólica digital e aparelho de som com CD e k7, bem como telefone, com chamada a ramal e linha externa. Tais recursos se fazem essenciais tanto ao planejamento, ao desenvolvimento e a avaliação do trabalho pedagógico, quanto para o contato efetivo da classe hospitalar, seja com a escola de origem do educando, seja com o sistema de ensino responsável por prover e garantir seu acesso escolar. ((BRASIL, 2002, p. 16).
\end{abstract}

O documento discorre sobre a importância de se utilizar os recursos de Tecnologia da Informática e comunicação- TICs, tanto para o desenvolvimento das atividades escolares, como para manter e fortalecer o vínculo com o ambiente escolar, incluindo todas as inovações tecnológicas como instrumentos de suporte da prática pedagógica, desde o ato de planejar até sua consecução, trazendo através desses instrumentos a realidade exterior para que o aluno não seja excluído dos ambientes externos ao hospital.

Isso é de suma importância para que o estudante não perca o vínculo com a coletividade discente, podendo ser agendadas, dentro das limitações, possibilidades e aconselhamento médicos que o pedagogo possa trazer, de forma individualizada, os colegas do estudante internado, como forma de manter essa vinculação com o mundo exterior e a sensação de pertencimento do aluno internado, mesmo que não esteja tendo a mesma aplicação de estratégias e metodologias da sala de aula regular. Este é um momento de grande sensibilidade emocional para o estudante e esse acompanhamento solidificará sua interação com o máximo possível de situações que levem em conta a humanização do trabalho do pedagogo.

Como nem sempre o estudante já sai do ambiente hospitalar apto a retomar suas atividades escolares normais, cumpre ao pedagogo fazer o acompanhamento domiciliar, sendo este um momento de transição, onde é imprescindível o apoio e auxílio incondicional da família. Para este momento de transição, segundo a Secretária de Educação Especial do Ministério da Educação é necessário:

Providenciar em parceria com os serviços de saúde e de assistência social, mobiliário e/ou equipamentos adaptados de acordo com as necessidades do educando, como: cama especial, cadeira e mesa adaptadas, cadeira de rodas, eliminação de barreiras para favorecer o acesso a outros ambientes da casa e ao espaço, etc. (BRASIL, 2002, p. 17).

É importante ter um mobiliário adequado no momento de transição da criança e adolescente com equipamento adaptados para trazer para esse aluno-paciente um 
tratamento mais específico com sua necessidade. Numa sociedade cada vez mais cercada de aparato tecnológico de relativa facilidade de acesso, as Tecnologias da Informação e Comunicação (TICs) já se tornaram a principal ferramenta a ser usada desde os casos de internamento quanto no período transitório domiciliar. As TICs, pela facilidade de interação com os colegas, em aulas remotas, já são a forma primária de interação real do aluno.

Importante ressaltar que o pedagogo deve ter domínio sobre essas novas linguagens, para que o aluno volte a ter a autonomia necessária sobre sua própria aprendizagem, tornando o pedagogo um elo mediador, sem perder a importância e sim, orientando e apresentando ao estudante essas novas formas de ensino aprendizagem (CAMPOS, 2013).

Seja por que ângulo se analise o processo continuado de ensino, o pedagogo terá sempre um papel central na condução do estudante rumo à reintegração completa, em todas as suas dimensões. Adequação, ressignificação são as palavras que embasam o seu trabalho desde que inicia seu fazer pedagógico no ambiente hospitalar, passado pelo domicílio do estudante até reincorporá-lo a convivência escolar regular.

O pedagogo que passa pela experiência de melhorar sua prática pedagógica através de uma situação, amplia seus horizontes tanto como profissional quanto como ser humano, quebrando seus próprios paradigmas e saindo mais seguro da sua vocação e da sua capacidade como educador. Como citam Silva e Carvalho:

Os profissionais que atuam com a Pedagogia têm um papel fundamental na sociedade, este é o profissional que tem formação para trabalhar com a educação, já que conhecem os seus problemas e suas contextualizações. Por meio de diversas atividades pedagógicas, acompanha e intervêm no processo de aprendizagem do enfermo, além de fornecer subsídios para a compreensão do processo de elaboração da doença, em conjunto com a equipe médica pode esclarecer procedimentos e auxiliar a criança/adolescente na adaptação hospitalar, dando oportunidade para que os mesmos possam exercer seus direitos de cidadãos. (SILVA; CARVALHO, 2014, p.3).

A Pedagogia Hospitalar busca promover para a criança em situação de internamentos, bem-estar e qualidade de vida. Isso é um desafio de grandes proporções para qualquer docente, pois ele tem que estar apto a transformar a multidisciplinaridade numa realidade constante, para que seu trabalho surte o efeito desejado. Os pedagogos devem ter uma boa preparação, com curso voltando para essa área para que haja uma 
aprendizagem exponencialmente ampliada, garantindo o sucesso do aluno em todas as etapas, desde o ambiente hospitalar até sua completa reintegração na classe regular.

\section{METODOLOGIA}

Este estudo trata-se de uma revisão integrativa que possui a finalidade de ter resultados sobre determinada questão ou tema, de maneira ordenada e sistemática, permitindo o aprofundamento do conhecimento sobre o tema pesquisado, além de possibilitar a incorporação de evidências científicas e do pensamento crítico na prática (MENDES; SILVEIRA; GALVÃO, 2008).

A pesquisa bibliográfica é elaborada a partir de material já publicado, como livros, artigos, periódicos, internet, etc. Pode-se dizer que essa categoria de pesquisa é um tipo de revisão bibliográfica, ou levantamento bibliográfico. Nesse mesmo sentido, Minayo (2017) explica que os exemplos mais característicos desse tipo de pesquisa são investigações que se propõem à análise das diversas posições acerca de um problema.

A revisão integrativa tem o papel de integrar resultados, potencialmente a

construção da ciência, pois além de contribuírem com o desenvolvimento do estudo, quando feita de modo rigoroso e sistemático a partir do passo a passo estabelecido, permite a construção do conhecimento e o desenvolvimento teórico de pesquisas que podem ter aplicabilidade diretamente na prática e na política (WHITTEMORE; KNAFL, 2005).

De acordo com Whittemore e Knafl (2005) a potencialidade da pesquisa integrativa se destaca na construção de uma revisão criteriosa, a qual os autores caracterizam como sendo o próprio estado da arte sobre um tema, possibilitando o desenvolvimento da ciência e de novas teorias. A revisão integrativa permite uma abordagem mais profunda.

Para o delineamento dessa pesquisa, foi realizada busca por artigos em plataforma da SciELO utilizando as seguintes palavras-chave: pedagogia hospitalar e educação, nesta primeira filtragem foram encontrados io artigos. Já na segunda filtragem foi incluído a data como categoria de exclusão, delimitando como período os anos compreendidos entre 2016 a 2020. Nesta segunda filtragem, foram encontrados 04 artigos, dos quais or foi excluídos porque se afastaram da temática, restando 03 artigos selecionados e analisados para a análise integrativa. 
Quadro I - Distribuição dos artigos filtrados e selecionados na base de dados SciELO.

\begin{tabular}{|c|c|c|c|c|}
\hline Filtragem & Encontrados & Repetidos & Incluído & Excluído \\
\hline PRIMEIRA & Io & o & o & Io \\
\hline SEGUNDA & o4 & 4 & 3 & I \\
\hline TOTAL & I4 & I & 3 & II \\
\hline
\end{tabular}

Fonte: Próprio autor (2020).

Após a leitura dos artigos selecionados (quadro or) foi realizada a identificação deles (QUADRO o2) para posterior realização da análise e discussão dos dados.

Quadro 2 - Identificação dos artigos

\begin{tabular}{|c|c|c|c|}
\hline Título & Autor & Ano & Revista Publicada \\
\hline $\begin{array}{l}\text { A importância da classe hospitalar } \\
\text { Semear do Recife no processo de } \\
\text { continuidade da escolarização dos } \\
\text { estudantes/pacientes com câncer }\end{array}$ & $\begin{array}{l}\text { SANTOS, Raffael Bruno } \\
\text { Gomes dos; } \\
\text { CONCEIÇÃO, Cláudia } \\
\text { Cristina da; } \\
\text { CAVALCANTE, Tícia } \\
\text { Cassiany Ferro. }\end{array}$ & 2019 & $\begin{array}{l}\text { Revista Brasileira de } \\
\text { Estudos pedagógicos }\end{array}$ \\
\hline $\begin{array}{c}\text { As Vozes das Professoras na Pedagogia } \\
\text { Hospitalar: Descortinando } \\
\text { Possibilidades e Enfrentamentos }\end{array}$ & $\begin{array}{c}\text { SOUZA, Zilmene } \\
\text { Santana; ROLIM, } \\
\text { Carmem Lucia Artioli. }\end{array}$ & 2019 & $\begin{array}{l}\text { Revista Brasileira de } \\
\text { Educação Especial }\end{array}$ \\
\hline $\begin{array}{c}\text { Educação hospitalar: uma questão de } \\
\text { direito }\end{array}$ & $\begin{array}{l}\text { ROLIM, Carmem Lucia } \\
\text { Artioli. }\end{array}$ & 2019 & $\begin{array}{c}\text { Actualidades Investigativas } \\
\text { en Educación }\end{array}$ \\
\hline
\end{tabular}

Fonte: Próprio autor (2020).

\section{RESULTADOS E DISCUSSÕES}

A partir de informações contidas nos artigos científicos de Santos et. al (2019), Souza; Rolim (2019) e Rolim (2019), foi possível compreender os benefícios e contribuições no processo de aprendizagem das crianças hospitalizada, assim como, a promoção de melhoria na saúde física e emocional. 
Quadro 3- Delineamentos metodológicos e principais desfechos

\begin{tabular}{|c|c|}
\hline METODOLOGIA & PRINCIPAIS DESFECHOS \\
\hline $\begin{array}{l}\text { Método qualitativo, análise documental, observação } \\
\text { e entrevista. }\end{array}$ & $\begin{array}{c}\text { Foi possível perceber que o pedagogo tem um papel } \\
\text { fundamental na classe hospitalar, pois buscar levar } \\
\text { atividade com diálogo e dinâmica para o } \\
\text { aluno/paciente. }\end{array}$ \\
\hline $\begin{array}{c}\text { Pesquisa qualitativo de cunho } \\
\text { descritivo, estudo de caso, coleta de dados e entrevista } \\
\text { semiestruturada. }\end{array}$ & $\begin{array}{l}\text { O estudo apronta que o processo escolar no } \\
\text { ambiente hospitalar, traz uma atenção, um cuidar } \\
\text { trazendo para essa criança uma continuidade na } \\
\text { vida e em seu estudo. }\end{array}$ \\
\hline Estudo qualitativo. & $\begin{array}{c}\text { Destacou -se que o desenvolvimento da criança } \\
\text { envolve fatores biológico e socioculturais, que } \\
\text { trazem a relevância do tratamento, possibilitando a } \\
\text { importância da educação hospitalar }\end{array}$ \\
\hline
\end{tabular}

Fonte: Próprio autor (2020).

Com a revisão integrativa foi possível destacar a importância da Pedagogia Hospitalar e compreender os desafios enfrentados pelos pedagogos para dar continuidade ao estudo em situação de internamento hospitalar. Desta forma, segue como proposta o diálogo dos autores.

A Pedagogia Hospitalar é um processo educativo em que o profissional da área atua fora do espaço escolar, o que traz desafios e possibilita a construção de novos conhecimentos e atitudes. Nesse sentido, a Pedagogia e os pedagogos rompem as barreiras das salas de aula consideradas tradicionais e ocupam espaços alternativos de escolarização. (SANTOS et al, 2019, p.635).

A Pedagogia Hospitalar vai além da sala de aula trazendo vivências e a continuidades do estudo para aquele que necessitam de um atendimento hospitalar, buscando possibilidades na aprendizagem e no desenvolvimento das crianças.

Destacamos que ensinar exige um planejamento da ação, mas o planejamento nunca é fechado, é sempre passível de mudanças, principalmente no ambiente hospitalar -Ensinar é um ato que envolve interação a compartilhamento entre os envolvidos, seja entre professor-aluno, aluno -professor e até mesmo entre aluno-alunoll. (SANTOS et al, 


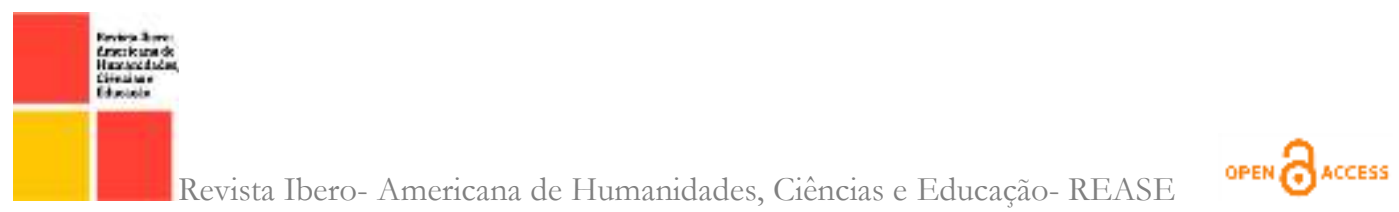

2019, p. 643).

O planejamento das aulas hospitalares deve ser feito de acordo com que o aluno necessita, como está seu desenvolvimento no conteúdo, o que é preciso melhora, buscar ter a interação do aluno com o pedagogo nesse compartilhando de conhecimento.

As práticas pedagógicas realizadas com as crianças hospitalizadas devem estabelecer um elo com a escola de origem. Esse elo acontece quando, na classe hospitalar, trabalham-se os mesmos conteúdos da escola regular com o estudante/paciente, tendo em vista a importância de dar continuidade aos conteúdos abordados durante o ano escolar em que se encontravam antes da doença (Santos et al, 2019, p.64I).

Essa criança volta a acompanhar as atividades de maneira mais abrangente sem dificuldades. O trabalho do pedagogo é garantir que as crianças e adolescentes continuem aprendendo e acompanhando o conteúdo escolar fortalecendo um vínculo entre escola e o hospital, desta forma, o profissional pedagogo terá o conhecimento necessário para conduzir a criança auxiliando em seu desenvolvimento. Este diálogo entre as instituições é estritamente importante, assim seu retorno ao espaço escolar será mais tranquilo.

De acordo com Souza et al (2019) ressalta que a brinquedoteca em ambiente hospitalar traz em sua essência a finalidade do brincar e do socializar, destacando o olhar para o desenvolvimento da criança no âmbito físico, emocional e cognitivo. Todavia, não podemos deixar de salientar outros pontos essenciais na vida da criança que são: o social e cultural, também descrito pelo autor, pois envolvem o desejo de aprender e conhecer como movimento constitutivo do desenvolvimento humano, o que nos leva a pensar na garantia da continuidade do aprendizado escolar.

Para Rolim (2019), no processo de internação hospitalar a criança experimenta dores e sofrimentos advindos de fragilidades orgânicas, temporárias ou permanentes com diferentes intensidades. Sua rotina não é a mesma, protocolos médicos são agora incluídos, outras necessidades fazem parte de sua realidade e exigem modificações em seu modo de viver, e com a ação afirmativa do pedagogo ao possibilitar a ludicidade e a continuidade das atividades escolares este sofrimento acaba sendo esquecido nem que seja por alguns instantes, e isto auxiliar na recuperação e na autoestima do paciente.

O momento de interação com o pedagogo é muito importante para essa criança que 
está fora de seu habitat natural que precisa se adaptando nessa nova rotina, o lúdico vivenciando dentro do hospital é uma forma que a criança ou adolescentes tem de expressar seu sentimento, desejo ou angústia. O brincar e o imaginar favorece a esse paciente um desenvolvimento emocional, capaz de amenizar o medo do tratamento e trazendo melhoras.

O pedagogo tem que estar disposto para interagir também com os colaboradores que ficam perto das crianças, e conhecer a história de cada uma, respeitando sua singularidade, limites e fragilidades, desta forma, conseguira atingir seu objetivo profissional que é possibilitar o desenvolvimento da criança ou adolescente naquele ambiente hostil.

Por fim, de acordo com o que foi estudado nos artigos, foi possível constatar a partir dos pensamentos dos autores abordados que o pedagogo é crucial no que diz respeito à política de educação em ambiente hospitalar. O pedagogo torna-se fundamental para o processo de ambientação, facilitando a qualidade de vida do educando hospitalizado no processo de ensino e aprendizado que busca se desenvolver integralmente dentro de suas necessidades.

\section{CONSIDERAÇÕES FINAIS}

O estudo dos artigos incluídos nesta revisão integrativa foi de grande relevância para a construção da temática, pois possibilitou um tipo de estudo que corresponde a um método de pesquisa científica de modo sistemático e amplo, favorecendo a caracterização e divulgação do conhecimento produzido (SILVEIRA, ZAGO, 20I6).

A Pedagogia Hospitalar ao atender crianças e adolescentes hospitalizados efetiva o direito que estes possuem a um ensino e educação de qualidade. Assim, esta pesquisa contribuiu para melhor conhecimento acerca da atuação do pedagogo neste ambiente, buscando sempre trabalhar de maneira multidisciplinar com a equipe multiprofissional, a escola e a família, atingindo, portanto, os objetivos vislumbrados.

A Pedagogia Hospitalar é uma área nova, desafiadora, diferenciada, que a cada dia vai ganhando espaço na área da educação, que possibilita levar o conhecimento, dignidade e qualidade de vida para crianças e adolescentes, o aluno enfermo passa a compreender seu 
tratamento, ao vivenciar momentos lúdicos, como uma música, leitura ou interação com o Pedagogo, criando um momento de descontração. O lúdico vivenciado dentro do hospital é uma forma de amenizar o tratamento da criança, levando um momento único em se aprende e leva conhecimento com brincadeiras e jogos dinâmicos, ajudando a compreender melhor seu tratamento e recuperação. O papel do pedagogo é de promover mudança e desenvolver uma aprendizagem lúcida para as pessoas e a sociedade.

Esta é uma temática muito abrangente, pois a Pedagogia Hospitalar extrapola qualquer paradigma de ensino regular, e exige do pedagogo uma preparação intensa, um comprometimento total e uma especialização que lhe permita conhecer desde as bases legais, históricas até a aplicação prática do ensino humanizado. Portanto, este trabalho não se finda aqui, pois tem muito a ser pensado, pesquisado e discutido a cerca desta temática que é bastante pertinente na área da pedagogia.

\section{REFERÊNCIAS}

BRASIL, Ministério da Educação. Secretaria da Educação Especial. Classe Hospitalar e atendimento pedagógico domiciliar: estratégias e orientações. Brasília - DF. 2002. Disponível em: http://www.dominiopublico.gov.br/download/texto/meooo423.pdf. Acesso em: 23 Out. 2020.

BRASIL, Ministério da Educação. Constituição da República Federativa do Brasil, 1998. Disponível em: http://www.trtsp.jus.br/legislacao/constituicao-federal-emendas. Acesso em: 23 Out. 2020.

BRASIL, Estatuto da Criança e do Adolescente. Lei no 8.089, de 13 de julho de 1990. Disponível em: http://www.conselhodacrianca.al.gov.br/sala-deimprensa/publicacoes/ECA\%20ATUALIZADO.pdf/view. Acesso em: 28 Out. 2020.

BRASIL, Lei Federal no 9394/96. Estabelece as Diretrizes e Bases da Educação Nacional, Brasília, 1996. Disponível em: http://www.planalto.gov.br/ccivil_03/leis/L9394.htm. Acesso em: 23 out. 2020.

CAMPOS, Gleisy Viiera. Classe Hospitalar, inclusão e aprendizagem: uma experiência mediada pelas tecnologias da informação e comunicação. Revista Extensão \& Cidadania, Vitória da Conquista,v.I,p.21-40, jul/dez.2013.Disponível em: http://periodicos.uesb.br/index.php/recuesb/article/viewFile/5402/pdf_319. Acesso em: 24 out. 2020. 
SANTOS. Raffael Bruno Gomes dos; CONCEIÇÃO. Cláudia Cristina da; CAVALCANTE. Tícia Cassiany Ferro. A importância da classe hospitalar Semear do Recife no processo de continuidade da escolarização dos estudantes/paciente com câncer. Revista Brasileira de Estudos pedagógico, Brasília,v.1oo,n.256p.633-65o,set./dez.2019. Disponível em: http://dx.doi.org/Io.24109/2176-6681.rbep.iooi256.4068. Acesso em: or Jan.2021.

ESTEVES, Cláuia. Pedagogia hospitalar: um breve histórico, s/d. Disponível em http://portal.mec.gov.br/seesp/arquivos/pdf/livro9. Acesso em: 25 de out. 2020.

FRANCO, Maria Amélia; LIBÂNEO, José Carlos; PIMENTA, Selma Garrido. Elementos para reformulação de diretrizes curriculares para cursos de Pedagogia. Cadernos de Pesquisa [online], v. 37, n.130, p. 63-97, jan/abr. 2007. Acesso 24 de out.2020.

MARKONIS \& LAKATOS. Metologia do Trabalho Científico. São Paulo. Vozes. 2015. Acesso em 27 de Nov.2020.

MENDES, Karina dal Sasso; SILVEIRA, Renata Cristina de Campos Pereira; GALVÃO, Cristina Maria. Revisão integrativa: método de pesquisa para a incorporação de evidências na saúde e na enfermagem. Texto \& Contexto enfermagem, Florianópolis , v.17,n.4,p.758Acesso em 26 de Nov.2020.

MINAYO, Maria Cecília de Souza. O desafio do conhecimento: Pesquisa Qualitativa em Saúde. São Paulo: Hucitec-Abrasco. 2017. Acesso em 23 de Nov.2020.

MATOS, Elizete Lucia Moreira; MUGIATTI, Margarida Maria Teixeira F. Pedagogia Hospitalar: a humanização integrando educação e saúde.Petrópolis: Vozes, 2007. Acesso em Is de Dez. 2020.

MELO, Damaris Caroline Queved.; LIMA, Vanda Maria Machado. Professor na Pedagogia Hospitalar: Atuação e Desafios. Colloquium Humanarum, Presidente Prudente, v. 12, n. 2, p.I44-152, abr/jun, 2015. Acesso em 9 de Dez.2020.

OTEIRO, Letícia Souza; DUTRA, Maria Carolina; SILVA, Paula Jaconine; FANTACINI, Fernandes. Pedagogia Hospitalar: conhecendo as suas modalidades de atendimento. Research, Society and Development, v.5, n.I, p.18- 32, 2017. Acesso em 20 de Nov.2020.

ROLIM, Carmem Lucia Artioli. Educação hospitalar : uma questão de direito. Revista Actualidades Investigativas em Educacion. Este número se publica el i de enero de 2019. Dol: https://doi.org/ro.15517/aie.vigir.356oo. Acesso em 02 de Jan.2021.

SILVA, A. C. da; CARVALHO, P. H. S. de. Pedagogia hospitalar: pedagogo em um 
ambiente diferenciado. Cadernos da Escola de Educação e Humanidades, Curitiba, v.8, p.I-I6, 2014. Disponível em: http://revistas.unibrasil.com.br/cadernoseducacao/index.php/educacao/article/dow nload/62/58. Acesso em: 24 out. 2020.

SILVA, Silvana Aparecida Siena; FANTACINI, Renata Andrea Fernandes. Pedagogia Hospitalar: a ação pedagógica em hospitais pediátricos. Revista Educação Batatais, v. 3, n. I, p. 31-52, junho, 2017. Disponível em:

$\langle$ claretianobt.com.br/download?caminho=/upload/cms/revista/sumários/248.pdf $\rangle$. Acesso em: 8 nov. 2020 .

SOUZA, Zilmene Santana; ROLIM, Carmem Lucia Artioli.As Vozes Das Professoras Na Pedagogia Hospitalar : Descortinando Possibilidades e Enfrentamentos. Revista Brasileira de Educação Especial,v.25,n3,p.403-420,Jul.- Set.,2019. Acesso em: 03 de Jan. 2021.

WHITTEMORE, Robin; KNAFL, Kathleen. The integrative Review: updated methodology. Journal of advanced nursing, v.52, n.5, p. 546-553, 2005. Disponível em: https://www.ncbi.nlm.nih.gov/pubmed/1626886r. Acesso em i9 Dez. 2020. 